\title{
POR UMA EPISTEMOLOGIA DO SER A PARTIR DA AMÉRICA-LATINA O NOVO CONSTITUCIONALISMO LATINO-AMERICANO E A BUSCA PELA LIBERTAÇÃO DA DIVERSIDADE
}

\author{
POR UNA EPISTEMOLOGÍA DE SER DE AMÉRICA LATINA - EL \\ CONSTITUCIONALISMO AMERICANO NUEVA AMÉRICA Y LA BÚSQUEDA DE \\ LA LIBERACIÓN DE LA DIVERSIDAD
}

${ }^{1}$ Heleno Florindo Da Silva

\begin{abstract}
RESUMO
A América Latina no decorrer das últimas décadas vem, sistematicamente, passando por inúmeras transformações constitucionais que, em seu contexto global, são frutos de movimentos sociais de luta, ou seja, por debates filosóficos, políticos e socioculturais, acerca da necessidade de transformação de sua realidade periférica, de modernidade tardia, enquanto construção política, jurídica e social da Modernidade. A partir dessas premissas, o start desse cenário de rompimento com o paradigma Moderno de construção sócio-política do Estado, pode ser visto na Constituição Brasileira de 1988 e seu ápice com a Constituição Boliviana de 2009. Portanto, desse contexto de busca por transformação paradigmática, através de diálogos cada vez mais plurais, que o presente trabalho buscará demonstrar como uma epistemologia latino-americana, construída, nos dizeres de Boaventura de S. Santos, no Sul e pelo Sul Global, pode ser compreendida como instrumento de transformação constitucional de uma sociedade. Todas essas discussões inauguram a possibilidade de uma nova perspectiva para os teóricos do direito que se preocupam com a construção política, social e, sobretudo, filosófica do Estado e das Constituições na Modernidade. Assim, fala-se no surgimento de um novo constitucionalismo, que rompe com as Teorias modernas sobre o Estado, bem como sobre a Constituição, um constitucionalismo de emancipação social, de resgate, de libertação, de desencobrimento detodos aqueles que foram, violentamente, excluídos e estigmatizados pela construção da Periferia pelo Centro moderno. Portanto, apoiados na visão metodológica do múltiplo dialético, e a partir de uma racionalidade latino-americana, verdadeira epistemologia do sul, que buscaremos discutir os desdobramentos e os fundamentos do que hoje se convencionou chamar de Novo Constitucionalismo Transformador, Democrático, Latino-Americano, a fim de que, ao final, nos seja possível concluir pelo surgimento de uma nova epistemologia do Ser construída a partir das mais recentes discussões constitucionais latino-americanas.
\end{abstract}

Palavras-chave: Modernidade, Novo constitucionalismo latino-americano, Epistemologia do sul

${ }^{1}$ Doutorando em Direitos e Garantias Fundamentais pela Faculdade de Direito de Vitória, e Professor do Centro de Evolução Profissional, CEP - Vitória - ES, (Brasil). E-mail: hfsilva16@hotmail.com 


\section{RESUMEN}

América Latina en las últimas décadas se ha estado sistemáticamente a través de numerosos cambios constitucionales que, en su contexto global, son el fruto de los 142 movimientos de lucha social, es decir, por los debates filosóficos, políticos y socioculturales, de la necesidad de una transformación su realidad periférica de la modernidad tardía, como una construcción política, jurídica y modernidad social. A partir de estas premisas, el inicio de este escenario con la interrupción paradigma moderno de la construcción socio-política del estado se puede ver en la Constitución brasileña de 1988 y su culminación con la Constitución boliviana de 2009. Así que desde ese contexto búsqueda de paradigma de transformación a través del diálogo cada vez más plural, que este documento tiene como objetivo demostrar cómo una epistemología latinoamericana, construida en Boaventura de dichos de S. Santos, el Sur y el Sur Global, se puede entender como un instrumento constitucional de transformación la sociedad. Todas estas discusiones inauguran la posibilidad de una nueva perspectiva a los teóricos del derecho que se preocupan por la construcción política, social y, sobre todo, el estado filosófico y Constituciones de la Modernidad. Así, se habla de la aparición de un nuevo constitucionalismo, que rompe con las teorías modernas sobre el Estado y sobre la Constitución, uno constitucionalismo de la emancipación social, la redención, de la liberación, de desocultamiento de todos los que estaban con violencia excluidos y estigmatizados por la construcción de la periferia por el centro moderno. Por lo tanto, con el apoyo de la vista metodológico de múltiples dialéctico, y desde una racionalidad estadounidense, verdadera epistemología sur de América, que tratan de discutir los avances y los cimientos de lo que hoy es comúnmente llamado el constitucionalismo transformador nuevo, Demócrata, Latinoamericano, por lo que al final se pudo concluir por la aparición de una nueva epistemología de ser construido a partir de los más recientes debates constitucionales latinoamericanos.

Palabras-claves: La modernidad, Nuevo constitucionalismo latinoamericano, Epistemología del sur 


\section{INTRODUÇÃO}

Vivenciamos ${ }^{1}$ nas últimas décadas um período de grandes mudanças, que nos obriga, entre outras coisas, a realizar um empenho neste novo milênio na busca por estarmos inseridos neste cenário de grande mundialização neoliberal, mas, sem deixarmos de estar conscientes, bem como de agirmos no âmbito cultural da diversidade e da legitimidade local, realidades ínsitas a um mundo totalmente interligado.

É um momento, portanto, que nos obriga repensar a realidade, a fim de que seja possível construirmos um projeto social e político contra hegemônico (a partir do Sul Global), capaz de reordenar as relações tradicionais entre Estado e Sociedade, ou seja, entre uma ética universalizante e um relativismo cultural, entre uma razão prática e uma filosofia do sujeito.

Nestes termos, é possível perceber que é deste contexto atual, multifacetado, que surge a necessidade de elaboração de um diálogo entre um discurso de integração e um discurso de diversidade, ou seja, entre as formas tradicionais da modernidade e as experiências diversas, plurais, heterogêneas, não-formais, de conhecimento, de modo de vida, de jurisdição.

Ressalta-se, que a partir dessas premissas acerca da realidade atual, é fundamental destacar, também, que na presente contemporaneidade, as novas formas plurais e libertárias, de matriz contra hegemônica, de legitimação social, que veem surgindo de amplos e diversos movimentos sociais, cujo objetivo está na transfiguração do Estado e de sua Constituição, elementos de efetivação e distribuição representativa do poder do Estado, como se verifica, conforme se verá abaixo, nas discussões acerca do novo constitucionalismo latino-americano.

A partir de então, apoiados na visão metodológica do múltiplo dialético2, o presente trabalho será desenvolvido com o objetivo para apresentar resposta ao presente problema de pesquisa: é possível percebermos, através da análise do novo constitucionalismo latino-americano e do direito fundamental à diversidade, o surgimento de uma nova epistemologia do ser, construída a partir do Sul - e pelo Sul - Global, compreendida como instrumento de transformação sóciopolítica e constitucional de uma sociedade?

\footnotetext{
${ }^{1}$ Como ponto de referência para a construção do presente texto será usada linguagem pessoal, na primeira pessoa do plural, haja vista o objetivo do presente trabalho ser compreender a necessidade de "nós", latino-americanos, observarmos nossas peculiaridades enquanto diversidade epistemológica, algo refletido na Filosofia do Direito Latinoamericana, em diálogo com o paradigma euro-norte americano de cariz colonizador. Desta feita, em que pese o melhor estilo de construção narrativo-metodológica, ser o impessoal, por tais motivos, optou-se pelo presente estilo de narrativa.

2 Para um aprofundamento acerca do método do Múltiplo Dialético, ver KROHLING, Aloísio. Dialética e Direitos Humanos - múltiplo dialético: da Grécia à Contemporaneidade. Curitiba: Juruá Editora, 2014.
} 
A partir de então, na primeira parte do presente trabalho, buscaremos analisar o fenômeno daquilo que se entende como pluralismo epistemológico, bem como a necessidade de se reconhecer um direito fundamental à diversidade, o que será feito a partir do sul global, sobretudo e principalmente, do contexto político, social e cultural, da América Latina.

Já na segunda parte, analisaremos as novas tendências constitucionais latino-americanas e, em especial, o que se convencionou chamar de novo constitucionalismo latino-americano, para, com isso, tentarmos extrair dessa nova perspectiva, alguns instrumentos para a construção de uma nova epistemologia do ser.

Portanto, com o presente trabalho buscamos contribuir para o atual debate político, social e cultural, acerca da pluralidade, da diversidade e da necessidade de convivência entre seres completamente diferentes a fim de se alcançar o bem comum, desenvolvendo um olhar múltiplo dialético da América Latina, de sua diversidade e de seus recentes movimentos constitucionais.

\section{O DIREITO FUNDAMENTAL À DIVERSIDADE: UMA ANÁLISE A PARTIR DO PLURALISMO EPISTEMOLÓGICO DO SUL ${ }^{3}$ (AMÉRICA LATINA)}

É a partir desse cenário, conforme destacado acima, de verdadeira crise, um período de grandes mudanças, período de verdadeira crise civilizatória4, fruto daquilo que a modernidade impôs ao mundo, como único padrão político, econômico, social e cultural possível, que necessariamente deveria ser partilhado por todos, e que caminha para autodestruição, que partiremos para análise do direito fundamental à diversidade a partir do contexto político-social latino-americano.

\footnotetext{
3 Sob essa perspectiva, Boaventura de Sousa Santos afirmará a necessidade que enfrentamos hoje, no contexto global, de aprender com o sul, haja vista ser constituído de países, sem sua grande maioria, que sofreram - e ainda sofrem - as mazelas de 500 anos de desenvolvimento do capitalismo global do colonizador, como única forma de sustentação da modernidade europeia, concluindo, a partir daí, que: "O primeiro passo é aprender com o Sul. O sul se constitui de povos, países e nações que mais têm sofrido com o desenvolvimento do capitalismo global, porque se mantiveram como países subdesenvolvidos, em desenvolvimento permanente, sem chegar nunca ao marco dos países desenvolvidos. E por isso, aprender com o Sul significa que a compreensão do mundo é muito mais ampla que a compreensão ocidental do mundo" (2009, p. 196 - tradução nossa).

4 Neste sentido, Lander aponta que "para amplos movimentos sociais em todo o planeta está cada vez mais claro que confrontamos uma profunda crise civilizatória, que estamos diante da crise terminal de um padrão civilizatório baseado em guerras sistemáticas pelo controle e submissão/ destruição da natureza (2010, p. 3 - tradução nossa).
} 
Portanto, é o momento de pensarmos alternativas a esse modelo ideologizante, homogeneizante e uniformizador, surgido na modernidade euro norte-americana, imposta ao restante dos povos, através de um processo colonizador que se transfigura durante os século, mas sem deixar de impactar a diversidade.

E é com essa perspectiva que uma nova racionalidade - que é milenar, mas que estava encoberta, pelo colonizador europeu, pela racionalidade moderna desde o "descobrimento das Américas" - começa a ser discutida e constitucionalizada na América Latina, principalmente, a partir dos países andinos, de modo que já e possível percebê-la como um instrumento de resgate de uma epistemologia do ser a partir do sul global.

Uma racionalidade que está pautada em preceitos indígenas, em conceitos e modos de ver a vida, de viver a vida, sob um prisma totalmente diverso da hiper competição dos dias atuais.

A busca pela felicidade não está no consumo desenfreado - eixo de um modelo econômico cujo fim é um mercado do capital globalizados - mas numa vida de plenitude sumak kawsay6-, ou seja, naquilo que se convencionou chamar de buen vivir.

Contudo, essa vida de plenitude não é possível de ser alcançada a partir do sistemamundo em que vivemos - pautado em competição, na busca desenfreada pelo acúmulo de capital, num sentimento de violência endêmica, de medo do outro, do diferente, do diverso - de modo que há necessidade de mudarmos as estruturas do atual modelo de Estado.

\footnotetext{
${ }^{5}$ Uma análise crítica desse cenário pode ser vista em Wolkmer, para quem "Diante dos processos de dominação e exclusão produzidas pela globalização, pelo capital financeiro e pelo neoliberalismo que vem afetando substancialmente relações sociais, formas de representação e de legitimação, impõem-se repensar politicamente o poder de ação da comunidade, o retorno dos agentes históricos, o aparecimento inédito de direitos relacionados às minorias e a produção alternativa de jurisdição, com base no viés interpretativo da pluralidade de fontes (2008, p. $182) "$.

${ }^{6}$ Segundo Macas Sumak Kawsay seria a vida em plenitude, "a vida em excelência material e espiritual". Segundo ele, essa ideia nasce da junção entre El Sumak - a plenitude, o sublime, excelente, magnífico, e etc. - e El Kawsay que nada mais é do que a vida, o ser, o estar, mas de forma dinâmica, ou seja, não como algo passivo, imposto por uma cultura dominante, hegemônica.
} 
Devemos, assim, rediscutir os dogmas do constitucionalismo moderno, não a partir de visões europeias das mais incríveis e difíceis teorias do Direito, do Estado ou da Constituição, mas sim, a partir de nós mesmos7, dos nossos conhecimentos, de nossa emancipação (MACAS, 2010, p. 16).

Aquela ideia de nação, fruto da modernidade europeia, corroborada na construção de uma identidade nacional homogeneizante, uniformizadora, representante de uma estética, um ser, pronto e acabado, que não poderia ser discutido, mas, tão somente, seguido, não é a mesma que a nova racionalidade constitucional latino-americana, que iniciamos as discussões, possui.

A construção latino-americana, em relevo, promove a separação da ideia de nação em duas frentes. Existe uma nacionalidade cívica, que nos identificaria como brasileiros, argentinos, ingleses, espanhóis e assim por diante, e uma nacionalidade étnico-cultural. É a partir disso que Santos aponta que

\begin{abstract}
Não há um conceito de nação, há dois conceitos de nação e não há necessariamente um conflito entre eles. A concepção de nação cívica, de origem liberal, cidadã todos somos equatorianos, bolivianos, brasileiros, portugueses (este era o conceito liberal de cidadania e da nação cívica, geopolítica). Mas há um conceito étnicocultural (...). Uma nacionalidade que tem raízes étnico-culturais e que não colide, não cria, necessariamente, conflito com o primeiro conceito de nação (2010a, p. 5 tradução nossa).
\end{abstract}

Toda essa busca, resgate, dos valores encobertos pela modernidade europeia no contexto latinoamericano, de enorme diversidade étnico-cultural, política, econômica e social, corrobora uma tentativa de se resgatar no passado - de culturas milenares, tais como: as andinas, onde se destacam a Inca; a Asteca; a Maia; as Amazônicas, entre outras - uma racionalidade para o futuro, que seja mais respeitosa com a diversidade cultural da América Latina, bem como com a natureza8.

\footnotetext{
7 As principais formas de resistência ao modelo moderno e europeu de sociedade do capital - um modelo cada vez mais depredador, seja da natureza, seja do próprio homem - segundo Lander vêm do Sul, ou seja, dos países cujas culturas originárias foram encobertas pela europeia por mais de 500 anos. Assim, ele aponta que "as principais resistências a este modelo depredador, a este processo de acumulação por desapropriação, ocorre em povos e comunidades campesinas e indígenas em todo o planeta, particularmente no Sul” (2010, p. 2). Neste sentido, Boaventura também aponta como essas comunidades são amantes de seu país, como querem e lutam por seu país, participar e construir, juntos, um novo modelo de sociedade, um novo Estado, ou seja, destaca que "não tinha visto ainda gente tão nacionalista como os indígenas, amantes de seu país. Lutaram por seu país, morreram por seu país nas guerras da independência, nas lutas depois da independência; são equatorianos, são peruanos, são colombianos, mas, também, são aymaras, são quechuas, são shuar" (2010a, p. 5 - tradução nossa).

8 Sobre a necessidade de frearmos a modernidade europeia capitalista, do consumo em competição cada vez mais acirrado e necessário para a manutenção do próprio sistema, José Alberto Mujica Cordano, presidente da República Oriental do Uruguai, em discurso proferido na ocasião da conferência da Organização das Nações Unidas para assuntos climáticos (Rio+20), nos aponta o fato de que não restaria oxigênio a ser respirado no mundo, se os "Indianos tivessem a mesma quantidade de carros por família que os Alemães", e conclui, que "não se trata de mudarmos e voltar às épocas dos homens das cavernas, nem de termos um "monumento ao atraso"”, mas sim, que o desenvolvimento não pode ser contra a felicidade do homem, ou seja, tem que ser a favor da felicidade humana.
} 
Assim, a busca pelo bem viver, necessariamente, deve passar pelo desencobrimento (libertação) dos conhecimentos que foram encobertos ao longo dos séculos por aquilo que Dussel (1994) chama de "mito da modernidade".

Céspedes (2010, p. 10) também analisará a necessidade de resgatar o outro, o diverso, o diferente, encoberto pela hegemonia uniformizadora, homogeneizante e ideologizante do $e u$, para alcançarmos o bem viver, chegando a conclusão de que

Viver bem é recuperar a vivência de nossos povos, recuperar a cultura da vida e recuperar nossa vida em completa harmonia e respeito mútuo com a mãe natureza, com a Pachamama, onde tudo é Vida, onde todos somos uywas, criados da natureza e do cosmos, onde todos somos parte da natureza e não há nada separado, onde o vento, as estrelas, as plantas, as pedras (...) são nossos irmãos, onde a terra é vida em si, bem como o lugar de todos os seres vivos9 (tradução nossa).

Através dessas discussões é possível perceber que o modo como essas culturas indígenas e campesinas latino-americanas - que se embasa na busca por um bem viver constroem ou reconstroem sua racionalidade para a vida, se corrobora na ideia de que cada cultura conserva em si, sua própria identidade, que não pode ser relegada por um modelo, uma identidade nacional, homogênea, desenvolvimentista e uniforme, do ser 10.

Portanto, na cosmovisão dos povos originários latino-americanos, segundo Huanacuni, "não existe um estado anterior ou posterior de subdesenvolvimento ou de desenvolvimento, como condição para se alcançar uma vida desejável, tal como ocorre no mundo ocidental", europeu e norte americano, mas, ao contrário, há todo um esforço para se construir as condições materiais e espirituais necessárias a criar e manter um bem viver, "que se define também como vida harmoniosa e em permanente construção" (2010, p. 19 - tradução nossa).

\footnotetext{
9 Diante disso, Céspedes conclui que essa racionalidade latino-americana discutida não buscará, num primeiro momento, falar de justiça social, "porque quando falamos de construir uma sociedade com justiça social, estamos falando unicamente das pessoas - humanos - e isso é excludente" (2010, p. 11).

10 Essa ideia é percebida por Macas quando chega a conclusão de que "toda sociedade é o resultado de um processo social, econômico, político, cultural, histórico determinado. Os povos ou as nações, (...). os seres humanos, são o produto da vida em sociedade” (2010, p. 14 - tradução nossa).
} 
Antes de continuarmos a análise dessa nova visão latino-americana de pacto social, de um constitucionalismo da diversidade, é necessário explicar algumas ideias que lastreiam toda essa racionalidade, tais como: o símbolo cultural Pachamama, sendo que é preciso compreender, para tanto, a etimologia dessa palavra, ou seja, é necessário compreender, por exemplo, o que é Pacha.

De um modo geral, para as culturas indígenas e campesinas andinas, Pacha é um termo plurissignificativo e multidimensional, pois todas as formas de existência vêm a ser a síntese das forças que movem a vida, ou seja, das forças cósmicas e telúricas11, do tempo e do espaço e forças que vão além disso. Huanacuni destaca sobre esse termo que

A palavra Pacha tem essa concepção, pois representa a união de ambas as forças: $P a$ que vem de Paya - que significa dois - y Cha que vem de Chama - que significa força. Duas forças cósmico-telúricas que interatuam para poder expressar isto que chamamos vida, como a totalidade do visível (Pachamama) e do invisível (Pachakama) 12 (2010, p. 21 - tradução e grifos nossos).

A ideia por detrás do símbolo cultural Pacha não se restringe ao modelo de espaçotempo da racionalidade moderna europeia, de modo que há que ser destacado que enquanto espaço, Pacha é a junção das forças cósmicas - representadas pelo Alaxpacha e pelo Kawkipacha - e das forças telúricas - representadas pelo Akapacha e pelo Manqhapacha 13.

${ }_{11}$ Conforme analisado acima, para as culturas indígenas e campesinas dos Andes latino-americanos, embasadas em seus ancestrais, existem duas forças que movem tudo o que existe, uma força cósmica, divina, que vem do céu aos seres vivos, e uma força telúrica, que nasce da terra, que formará aquilo que eles entendem ser a Pachamama. Desse modo, é possível perceber que para essa cultura, essa racionalidade, essa cosmovisão andina, tudo o que existe no mundo possui vida, seja algo orgânico, seja algo inorgânico. Portanto, é da conversão dessas forças no decorrer do processo da vida, que todas as diferentes formas dessa vida surgem. Essas diferentes formas de vida passam a se relacionar com aquilo que nessa cosmovisão se entende como Ayni, a complementaridade, o equilíbrio, pois é a diferença, a diversidade, em equilíbrio, que completará o sentido da vida, do bem viver (HUANACUNI, 2010, p. 21 e 22).

12 Portanto, conforme conclui Huanacuni "para o ser andino esta palavra vai mais além do tempo e do espaço, implica uma forma de vida, uma forma de entender o universo que supera o tempo-espaço (o aqui e o agora). Pacha não só é tempo e espaço, é também a capacidade de participar ativamente do universo, submergir-se e estar nele" (2010, p. 22 - tradução nossa).

13 Alaxpacha representa a dimensão de um plano superior, ou seja, compreende o plano superior tangível, visível, onde se olham as estrelas, o sol, a lua, o raio. No ser humano, alaxpacha compreende o corpo invisível, o emocional, o etéreo. Por outro lado, Kawkipacha, a dimensão de um plano indeterminado, representa o mundo desconhecido, indefinido, o mundo que existe mais além do que é visível. O mundo andino concebe que existe vida mais além do universo visível. Se nos referirmos aos seres humanos, kawkipacha é aquilo que está mais além do corpo tangível, podemo-los chamar de 'essência da vida'. Enquanto força telúrica, Akapacha representa a dimensão, o espaço deste mundo em que vivemos, ou seja, corresponde a este mundo, onde se desenvolve toda a forma de vida visível, seja ela humana, animal, vegetal ou mineral. Em relação aos seres humanos, akapacha corresponde ao corpo físico e ao espaço da percepção humana consciente. Por fim, Manqhapacha é a dimensão do mundo de baixo, ou seja, se refere ao mundo de baixo, onde se acham as forças da mãe terra. O mundo andino concebe vida ao interior da terra. Em relação aos seres humanos, manqhapacha é o mundo interior, e no espaço de percepção humana, significa o subconsciente (HUANACUNI, 2010, p. 22). 
De outro lado, enquanto tempo14, Pacha é a junção das cinco formas de tempo segundo a racionalidade andina -, ou seja, o tempo que é presente (Jichapacha), o tempo que é passado (Nayrapacha), o tempo que é futuro (Jutirpacha), o tempo que é intenso (Sintipacha) e o tempo que é eterno (Wiñaypacha). É a partir disso que Huanacuni chega à conclusão de que

\begin{abstract}
É importante diferenciar as concepções a respeito da ideia de tempo entre o Ocidente e os Andes. Para o Ocidente o tempo é linear, vem de um passado, passa por um presente produto desse passado e vai para um futuro. No mundo andino o tempo é circular; se assume um presente, no entanto, que é contínuo, de modo que passado e futuro acabam se fundindo em um só ao final (HUANACUNI, 2010, p. 22 tradução nossa).
\end{abstract}

A racionalidade andina que fundamenta toda essa recente discussão constitucional trazida à luz pelas mais recentes Constituições latino-americanas, não concebe nada como estático, pois tudo está em um eterno movimento. Por isso, buscam a ideia de bem viver, que é viver a vida com mais brilho, plenamente, em um tempo que sempre será o presente.

Esse bem viver busca romper com a estética moderna europeia de vida, de realidade, de sociedade e, principalmente, de Estado e de sistema econômico15, haja vista a "noção de bem viver desprezar a acumulação como categoria central da economia, situando a vida nesta centralidade" (LEÓN T., 2010, p. 24), ou seja, o bem viver andino não é somente uma utopia para o futuro das próximas gerações, mas, ao contrário, é uma constante realidade presente.

Portanto, é possível perceber que o pluralismo epistemológico querido e necessário no contexto latino-americano, tem como objetivo central, dar fim a todos os movimentos de violação à cultura, à diferença, à diversidade, movimentos estes característicos de etnocídios (ALMEIDA, 2012, p. 72), de epistemicídios (SANTOS, 2011, p.87), verdadeiros genocídios étnico-cultuais (WOLKMER, 2008, p. 183).

\footnotetext{
14 Uma análise crítica sobre as construções teóricas que narram o tempo inerente aos processos sociais, sua duração, produção e reprodução, a partir de uma racionalidade ocidental, linear, causal e estrutural, ver TÀPIA, Luis. Tiempo, Poiesis y Modelos de Regularidad. In.: Pluralismo Epistemológico. La Paz: Muela del Diablo Editores, 2009, p. 177-192.

15 Isso pode ser percebido mais claramente em Gargarella e Courtis, 2009, p. 21, quando demonstram como asrecentes Constituições de Equador e Bolívia vêm romper com as tradições constitucionais da modernidade europeia - elitistas e individualistas -, que são, sobretudo, conforme nos aponta Magalhães (2012e, p. 13 e 14) pautadas na ideia da propriedade individualizada e uniformizada, bem como da família como algo a seguir um único padrão - o europeu.
} 
A partir de então, numa perspectiva a partir do Sul Global - representado aqui pela América Latina - um pluralismo epistemológico deverá, necessariamente, na busca por desenvolver uma cultura político-jurídica mas democrática, buscar meios de pensar e fomentar formas diversificadas de produção, e de reconhecimento, do conhecimento válido.

Saberes que partam de uma prática política que seja mais democrática e mais pluralista, que não só representem no papel, mas que se efetivem enquanto expressão do Direito à Diferença 16, de modo que o pluralismo seja visto como princípio de legitimidade política, jurídica e, sobretudo, cultural, alicerce do direito fundamental à diversidade.

O pluralismo epistemológico democrático, portanto, deve ser encampado como um dos instrumentos mais essenciais para o combate das mazelas ínsitas à globalização do mercado de consumo do capital neoliberal17, apto a legitimar uma estratégia contra hegemônica de afirmação de direitos fundamentais, dentre os quais está o direito à diversidade.

Será dessas premissas lançadas acima que buscaremos analisar o novo constitucionalismo latino-americano como fonte, verdadeiro instrumento, para a construção de uma nova perspectiva político-social, uma nova epistemologia do ser, ficada em ideais frutos de conhecimentos indígenas e que podem, resumidamente, ser compreendidos a partir de um símbolo, qual seja: "o bem viver”.

\footnotetext{
16 Sobre o "direito à diferença", Olivé destaca que se trata do direito que os indivíduos possuem de serem reconhecidos enquanto pertencentes de uma dada comunidade de sujeitos, seja ela cultural, política ou social, de modo que possam, a partir de então, desfrutar "(...) das condições apropriadas para que esta se preserve, sedesenvolva e floresça, de acordo com as decisões que seus membros tomem de maneira autônoma" (2004, p. 88-89).

17 Segundo Wolkmer, “(...) a interpretação e a prática da ideologia neoliberal, particularmente na América Latina,tem se projetado como concepção radical do capitalismo que tende a absolutizar o mercado, e a convertê-lo emmeio, em método e fim de todo comportamento humano racional. Segundo essa concepção, ficam subordinadosao mercado a vida das pessoas, o comportamento da sociedade e a política dos governos. O mercado absolutistanão aceita nenhuma forma de regulamentação. (...) o neoliberalismo acabou, na esteira dessas manobras,contribuindo para acelerar imensos desequilíbrios econômicos, elevadas taxas de desemprego, profundasdesigualdades sociais acentuados desajustes no cotidiano das comunidades locais e o genocídio cultural" (2008, p. 185).
} 


\section{O NOVO CONSTITUCIONALISMO LATINO-AMERICANO: EM BUSCA DEINSTRUMENTOS PARA UMANOVA EPISTEMOLOGIA DOSER.}

Tracejadas acima as principais características de uma nova racionalidade social, política, cultural e econômica, fruto de inúmeras revoluções sociais nos países de origem indígena e campesina da América Latina, cujo objeto, dentre outros aspectos, pode ser compreendido a partir do debate sobre a diversidade, é necessário destacar como tal perspectiva se desenvolveu nas últimas décadas.

Contudo, faz-se necessário, antes de mais nada, destacar o fato de que falar em constitucionalismo é falar, necessariamente, em segurança18, pois foi esse o viés pelo qual a modernidade viu a necessidade de criar as primeiras Constituições aos Estados modernos.

Nessa época de formação das primeiras Constituições as leis eram criadas por um parlamento eleito pelo voto censitário19, pois aos burgueses era dado o poder de alterar, ou não, a realidade social e econômica da época, eram eles os detentores do poder econômico, único mecanismo capaz de alterar, ou não, a Constituição.

Às demais pessoas, principalmente aos operários, aos trabalhadores braçais, restavam, tão somente, às punições, o medo do desemprego, a pobreza estrema e a criminalidade.

De modo diverso, o novo cenário constitucional latino-americano, mostra ao mundo europeu e norte-americano, a possibilidade de alcançarmos uma nova racionalidade social e política, principalmente em relação às decisões do Estado.

Portanto, após 500 anos de colonização, pós-colonização ou neocolonização, a América Latina encontra em sua ancestralidade indígena, campesina, negra e andina, o outro que existe em cada um de nós, de modo que, nas primeiras visualizações desse novo modelo constitucional - conforme as palavras de Vieira (2012) - é possível afirmar que se trata de um constitucionalismo a partir de uma racionalidade indígena e campesina, dando azo a uma nova conformação sociopolítica para o Estado.

\footnotetext{
18 Conforme destaca Magalhães “o constitucionalismo moderno surge da necessidade burguesa de segurança nas relações econômicas, nos contratos. Constitucionalismo significa, portanto, "segurança"” (2012e, p. 36).

19 Neste sentido, Burdeau e outros, apontam que "o direito de sufrágio não é considerado um direito inerente à qualidade do homem. O voto depende da capacidade dos indivíduos (...)" (BURDEAU e outros, 1995, p. 316 apud. MAGALHÃES, 2012e, p. 37). Uma das características que demonstrariam a capacidade de uma pessoa de vota e de ser votada estava na grandeza de sua fortuna pessoal, ou seja, acreditava-se, nessa época, que quanto mais rico fosse o sujeito, mais capaz para governar seria, por isso, haviam limitações financeiras e etárias discutidas acima.
} 
É a partir dessas premissas, que Baldi (2008) destacará que esse constitucionalismo latino americano, possuiu três grandes ciclos20, ou seja, esse modelo plural tem como origem um constitucionalismo multicultural (1982/1988), fruto das primeiras discussões acerca da insuficiência do modelo antigo em garantir direitos - de primeira, segunda ou terceira dimensão - para aquelas pessoas que não representassem os ideais - fosse com relação à cor da pele, a religião ou ao modo de viver - da cultura europeia, cristã e capitalista, imposta pelo colonizador - o que serviu para o reconhecimento de direitos indígenas específicos, bem como para a introdução, nos textos das diversas Constituições da época, da noção de diversidade cultural.

Em seguida, o autor destaca como segundo ciclo de formação desse constitucionalismo latino-americano em discussão, a ascensão do que se denominou na época, de constitucionalismo pluricultural (1988/2005), que surge como instrumento para o reconhecimento da existência de sociedades multiétnicas e de Estados Pluriculturais - um exemplo desse período é a Constituição Pluricultural da Venezuela de $1999_{21}$.

Como último ciclo de desenvolvimento desse constitucionalismo latino americano, Baldi (2008) destacará o constitucionalismo plurinacional surgido em 2006 no contexto da Declaração das Nações Unidas sobre direitos indígenas, bem como nos contextos das assembleias nacionais constituintes da Bolívia e do Equador, que concretizaram a formação dos primeiros modelos de constituições e de Estados Plurinacionais22.

\footnotetext{
20 Sobre os ciclos de formação do novo constitucionalismo latino-americano é importante ressaltar as palavras de Wolkmer e Fagundes (2011, p. 403) para quem esse novo cenário foi construído em três momentos, ou seja, “(...) um primeiro ciclo social e descentralizador das Constituições Brasileira (1988) e Colombiana (1991). (...) um segundo ciclo (...) participativo popular e pluralista, em que a representação nuclear desse processo constitucional passa pela Constituição Venezuelana de 1999”. E um terceiro ciclo - plurinacional comunitário - "passa a ser representado pelas recentes e vanguardistas Constituições do Equador (2008) e da Bolívia (2009)".

21 E mais, neste contexto, há o surgimento, também, da Convenção 169 da Organização Mundial do Trabalho, reconhecendo um catálogo de direitos indígenas, afro e outros de cunho coletivo aos indivíduos e povos cujo Estado a ratificasse - essa Convenção foi ratificada pelo Brasil pelo Decreto $n^{\circ} 5.051$, de 19 de Abril de 2004.

22 Sobre os ciclos de formação desse novo constitucionalismo latino-americano, é importante destacar que todas as discussões acerca desse novo cenário constitucional latino não nascem com o advento de uma única constituição. A história não é algo estanque, com data e hora para acontecer. O constitucionalismo da diversidade que emerge, portanto, é fruto, segundo Raquel I. Fajardo - de certo modo, corroborando as ideias de Baldi trazidas acima -, de vários ciclos de debates, cada qual representado por vários textos constitucionais, por onde se destaca que "o horizonte do constitucionalismo pluralista contemporâneo na América Latina passa por três ciclos: a) o constitucionalismo multicultural (1982 a 1988): composto pelas Constituições do Canadá de 1982, da Guatemala de 1985, Nicarágua de 1987 e do Brasil de 1988. A Constituição do Canadá teria inaugurado o multiculturalismo, pois abre um primeiro reconhecimento de sua herança multicultural e da incorporação dos direitos aborígines; b) o constitucionalismo pluricultural (1989 a 2005): inaugurado pelas Constituições da Colômbia de 1991, México de 1992, Perú de 1993, Bolívia de 1994, Argentina de 1994 e Venezuela de 1999; c) o constitucionalismo plurinacional (2006): inaugurado com o surgimento das Constituições do Equador de 2008 e da Bolívia de 2009" (2010, p. 25 apud. WOLKMER, 2013, p. 30).
} 
Em que pese Baldi (2008) destacar a construção do modelo constitucional latinoamericano em discussão através de uma evolução iniciada no constitucionalismo multicultural da década de 1980 - pois as constituições dessa época são exemplos de reconhecimento e proteção cultural (o que pode ser visto pelos arts. 231 e 232, da Constituição da República Federativa do Brasil de 1988) - existem entendimentos diversos, que ligam essa nova visão constitucional, originariamente, à Constituição Colombiana de 199123. É o que destaca Noguera-Fernándes e Diego, ao afirmarem que

$\mathrm{Na}$ Constituição colombiana aparecem, mesmo que imperfeitamente, mas claramente reconhecível, alguns elementos inovadores e diferenciados em relação ao constitucionalismo clássico, que mais tarde permearão e serão desenvolvidos nos processos constituintes equatoriano em 1998, venezuelano em 1999, e boliviano em 2006-2009 e, de novo, no Equador em 2007-2008. (...). A Constituição colombiana de 1991 é, por conseguinte, o ponto de partida do novo constitucionalismo no continente24 (2011, p. 18 - tradução nossa).

Apesar dessa forma de se pensar o constitucionalismo latino em discussão, ou seja, desse resgate do valor da constituição na promoção de uma sociedade mais justa, poder ser dissecada a partir desses ciclos, entendemos que a Constituição da Venezuela de 1999 possui extrema importância para a ponte entre o reconhecimento da diferença trazido pelo multiculturalismo canadense e a plurinacionalidade boliviana.

E mais, é a partir da Constituição da Venezuela de 1999 que o novo constitucionalismo latino americano começa a tracejar aquilo que Santos chamará de "reinvenção da democracia" (1998)25.

\footnotetext{
23 Sobre a formação do que hoje se discute como novo constitucionalismo latino-americano, bem como de Estado Plurinacional - que será trabalhado mais detidamente abaixo - Magalhães percebe a construção desse cenário de discussões fervilhantes, distintamente dos citados autores acima, ou seja, para ele "embora possamos encontrar traços importantes de transformação do constitucionalismo moderno já presentes nas constituições da Colômbiade 1991 e da Venezuela de 1999, são as constituições do Equador (2008) e da Bolívia (2009) que efetivamente apontam para uma mudança radical que pode representar, inclusive, uma ruptura paradigmática não só com o constitucionalismo moderno mas, também, com a própria modernidade" (2012e, p. 12).

24 Corroborando esse entendimento Pastor e Dalmáu concluem que "os novos processos constituintes latino-americanos tiveram início na Colômbia, no princípio da década de 1990, como fruto de reivindicações sociais anteriores” (2010, p. 9 - tradução nossa).

25 Sobre esse ponto em especial, é importante ressaltar que o novo constitucionalismo latino-americano advém desse objetivo - uma reformulação de conceitos formados na modernidade, tal como a ideia de democracia representativa - que aparece estampado nos textos constitucionais mais recentes do continente, qual seja: o de legitimar, bem como, expandir a democracia, surgindo ao contexto constitucional como resultado de lutas e de reivindicações populares por um novo modelo de organização do Estado e do direito (MORAES e FREITAS, 2013, p. 106 e 107).2013,p.106e107).
} 
Tal constatação pode ser vista pela ampliação da participação popular nas decisões tomadas pelo Estado a partir das recentes constituições latino-americanas representantes desse cenário constitucional em discussão26.

Todo esse movimento constituinte latino-americano, principalmente nos países de ancestralidade indígena e campesina andina, vem demonstrar que as novas Constituições neste contexto trazem um catálogo de direitos constitucionais que rompe com o paradigma geracional da modernidade eurocêntrica.

São textos, portanto, construídos a partir do (re)surgimento do indígena, do campesino, efetivamente, como um sujeito de direitos, com vez e vós no cenário político das decisões políticas, sociais e econômicas do Estado, frutos do reconhecimento da existência de um pluralismo epistemológico.

Acerca da ideia de pluralismo, muito embora já desenvolvida acima, é importante destacar, que o seu reconhecimento no Sul Global e a partir dele, possibilita a construção de uma perspectiva nova a essa expressão, pois

\begin{abstract}
Nessa perspectiva, o pluralismo comprometido com a alteridade e com a diversidade cultural projeta-se como instrumento contra hegemônico, porquanto mobiliza concretamente a relação mais direta entre novos sujeitos sociais e poder institucional, favorecendo a radicalização de um processo comunitário participativo, definindo mecanismos plurais de exercício democrático e viabilizando cenários de reconhecimento e de afirmação de Direitos Humanos (WOLKMER, 2008, p. 187).
\end{abstract}

A constitucionalização da diversidade, portanto, principalmente, através das Constituições da Venezuela, do Equador e da Bolívia, demonstra como o outro, violado, encoberto, esquecido, por aproximadamente 500 anos, pode passar a figurar como sujeito importante para as decisões sociais e do Estado, não somente com o depósito de seu voto para a escolha de representantes, mas como sujeito ativo, atuante, que deve e será ouvido no decorrer da história.

\footnotetext{
26 Acerca da importância da Constituição da Venezuela para a conformação desse constitucionalismo latino, Wolkmer (2013, p. 31 e 32) ressalta as inovações do constitucionalismo venezuelano trazidas em sua Constituição de 1999, demarcando-as como verdadeiros marcos na participação do povo em relação a formação, execução e controle da gestão pública. É o que determina o art. $6^{\circ}$, da Constituição da Venezuela de 1999 , para quem "O Governo da República Bolivariana da Venezuela e das entidades políticas que a compõem sempre será democrático, participativo, eletivo, descentralizado, alternativo, responsável e pluralista, com mandatos revogáveis" (tradução nossa).
} 
constitucionalismo que se pretende e se defende nessa nova perspectiva latino-americana, nos permite superar as leituras liberais, procedimentais ou instrumentais da modernidade27, abrindo espaço para que, por exemplo, a democracia não se restrinja a um devaneio social de um momento de luta contra os monopólios burgueses, ou contra a falta de concretização dos direitos fundamentais ou, ainda, contra as restrições impostas pela cultura globalizante do capital (LINERA, 2010, p. 11-24).

Ao analisar o momento de surgimento do novo constitucionalismo latino-americano, Grijalva aponta para um constitucionalismo plurinacional embasado em relações interculturais, que rompem com as estruturas do Estado nacional da modernidade, ao reconhecer que

O constitucionalismo plurinacional é ou deve ser um novo tipo de constitucionalismo baseado em relações interculturais igualitárias que redefinem e reinterpretam os direitos constitucionais e reestruturam a institucionalidade provenientes do Estado Nacional. O Estado plurinacional não é ou não deve se reduzir a uma Constituição que inclui um reconhecimento puramente cultural, (...), senão um sistema de foros de deliberação intercultural autenticamente democrática (2008, p. 50-51 - tradução nossa).

Essas novas tendências constitucionais, portanto, que corroboram o que vem sendo chamado de novo constitucionalismo andino se corrobora em um verdadeiro instrumento descolonizador, apto a nos garantir revisitar a ideia de democracia construída na modernidade.

Sobre esse interesse em relação à democracia - a busca por um novo sentido ao termo - desencadeado no atual cenário constitucional latino-americano, é importante destacar as palavras de Chivi Vargas sobre o surgimento de uma democracia intercultural, que reconhece e possibilita a manifestação política heterogeneamente, pois

\footnotetext{
democracia igualitária é a superação da democracia representativa do século XIX eda participativa do século XX, por uma democracia onde a igualdade material é o centro da atividade estatal, a igualdade formal se acha no baú da história hipócrita do constitucionalismo moderno (2010, p. 34 - tradução nossa).
}

\footnotetext{
27 É dessa constatação que podemos retirar um fato comum, qual seja, de que todas as deficiências apontadas ao marco do constitucionalismo moderno nacional convergem para uma origem comum, ou seja, às primeiras teorias do nacionalismo de cunho liberal, haja vista esse modelo se concretizar pela desconsideração do caráter político, não meramente étnico-cultural, de modo que os governos, as organizações, as instituições de poder, em seus discursos nacionalistas, não refletiam - e como o novo constitucionalismo latino-americano irá discutir - e ainda não refletem, o povo que lhe é subjacente, que lhe é "súdito". (MAIZ, 2012, p. 18). Diante desse fato, Tápia expôs uma série de crises que essa noção clássica moderna e nacional - de Estado, vem cotejando nos últimos anos, sendo que, segundo ele, uma dessas crises é a de correspondência entre os cidadãos e seu governo, ou seja, os membros do poder de um Estado não são ligados às várias culturas de uma sociedade, "se trata de uma crise de correspondência entre o Estado boliviano, a configuração de seus poderes, o conteúdo de suas políticas, por um lado, e, por outro, o tipo de diversidade cultural desenvolvida de maneira auto organizada, tanto ao nível da sociedade civil, quanto da assembleia de povos indígenas e outros espaços de exercício da autoridade política que não formam parte do Estado boliviano, senão de outras matrizes culturais excluídas pelo Estado liberal desde sua origem colonial, bem como em toda sua história posterior" (2007, p. 48 - tradução nossa).
} 
Todo o novo constitucionalismo latino-americano tem como objetivo, num primeiro momento, buscar uma fundamentação para a Constituição, ou seja, sua legitimidade, e somente, a partir daí, passa a se interessar pela sua efetividade e sua normatividade (PASTOR e DALMÁU, 2010, p. 18 - tradução nossa).

É daí que nasce a ideia de que esse cenário constitucional não possui um progenitor, um pai, ou seja, o novo constitucionalismo latino-americano “(...) é um constitucionalismo sem pais. Ninguém, exceto o povo28, pode se sentir progenitor da Constituição, haja vista a genuína dinâmica participativa e legitimadora que acompanha os processos constituintes" (DALMÁU,2008, p. 19 - tradução nossa) recentes na América Latina.

O novo constitucionalismo latino-americano - constitucionalismo da diversidade - se constitui em uma tentativa de ruptura com o paradigma atual de Estado - de matriz moderna e europeia -, bem como de epistemologia do ser, no momento em que estabelece, dentre outras coisas, que a unidade normativa de uma Constituição29, não necessariamente, representará uma uniformização social, política e cultural em torno de um modus vivendi hegemônico (SANTOS, 2010, p. 89).

Evidencia-se, portanto, que o constitucionalismo de matriz moderna, europeia, liberal, pautado na figura de um Estado nacional, não é mais integralmente satisfatório30, principalmente em um contexto de enorme diversidade étnico-cultural como a América Latina.

28 Corroborando essa ideia, Wolkmer e Fagundes destacam a marca dos movimentos sociais que dão origem ao novo constitucionalismo latinoamericano, demonstrando que "os movimentos pela refundação do Estado latino-americano surgem da exigência histórica por espaço democrático, congregam interesses a partir do abandono da posição de sujeitos passivos na relação social com os poderes instituídos" (2011, p. 395).

29 Analisando a uniformidade do direito de matriz moderna, nacional e europeia, à luz das recentes constituições latino-americanas que trazem a possibilidade de um pluralismo jurídico, Santos destaca que "depois de dois séculos de suposta uniformidade jurídica não será fácil para os cidadãos, organizações sociais, atores políticos, servidores públicos, advogados e juízes adotarem um conceito mais amplo de direito que, ao reconhecer a pluralidade de ordenamentos jurídicos, nos permite desconectar parcialmente o direito do Estado e o (re)conectar com a vida e a cultura dos povos" (2009, p. 197 - tradução nossa).

30 Ao descrever como o constitucionalismo moderno ocidental - europeu, liberal, cristão e masculino - não responde aos anseios de uma sociedade pluriétnica como a latino-americana, Chivi Vargas aponta para o fato de que "tem sido historicamente insuficiente para explicar sociedades colonizadas; não teve clareza suficiente para explicar a ruptura com as metrópoles europeias e a continuidade de relações tipicamente coloniais em suas respectivas sociedades ao longo dos séculos XIX, XX e parte do XXI" (2009, p. 58). 


\section{CONCLUSÃO}

O novo constitucionalismo latino-americano, fruto de inúmeras lutas sociais ao longo dos últimos anos, surge, neste sentido, como uma busca pela superação desse modelo homogeneizante e uniformizador da vida humana, fazendo emergir um conhecimento a muito esquecido, de ancestralidade andina, indígena, campesina, mestiça.

Um conhecimento plural, que não só reconhece o valor da diversidade, mas que a pratica como fonte primeira de sua existência, ou seja, uma epistemologia do ser, construída pelo Sul Global, e a partir daí, de cunho democrática, cujo principal marco é a formação de uma rede de solidariedade entre o eu e o outro, na formação de um novo Nós.

A partir de então, é possível concluirmos que na condução dessa nova perspectiva epistemológica, enraizada no que se chamou acima de novo modelo constitucional latinoamericano, o sujeito (Nós) deverá tomar alguns cuidados em sua relação com os outros sujeitos (Eles), pois deverá e pautar pelos ideias e alicerces da diversidade, enquanto direito fundamental do ser.

Portanto, sob o prisma epistemológico do direito fundamental à diversidade, os indivíduos devem ser: a) Dialógicos - pois a diversidade requer comunicação e deliberações permanentes entre as culturas; b) Concretizantes - pois deveremos buscar soluções específicas, e em tempo, para situações individuais e coletivas; e c) Garantistas - haja vista essas soluções surgirem por meio de deliberações, cujo marco de compreensão é o reconhecimento dos valores constitucionais institucionalizados pelos Direitos Humanos, dentre os quais, se destaca o direito fundamental à Diversidade 


\section{REFERÊNCIAS}

ALMEIDA, Lúcio Flávio Rodrigues de. Lutas sociais e questões nacionais na América Latina: algumas reflexões. Disponível em: <http://www.pucsp. br/neils/downloads/v17_18_lucio.pdf>. Acessado em: 20 de Agosto de 2014.

BALDI, César Augusto. Novo Constitucionalismo Latino-Americano. In: Jornal Estado de Direito. $\quad 32^{\mathrm{a} e d}$ Disponível em: <http://www.estadodedireito. com.br/2011/11/08/novoconstitucionalismo- latino-americano/>. Acessado em: 14 de Agosto de 2014.

CÉSPEDES, David Choquehuanca. Hacia La Reconstrucción Del Vivir Bien. In.: Sumak Kawsay: recuperar el sentido de vida. ALAI, no 452, año XXXIV, II época, Quito, Ecuador, febrero 2010.

CHIVI VARGAS, Idón M. Nueva Constitución y Desarrollo Normativo. In.: Agência Latinoamericana de Información América en Movimiento. Ano 2010. Disponível em: $<$ http://alainet.org/active/35872\&lang=es>. Acesso em: 16 de Setembro de 2014.

Os Caminhos da Descolonização na América Latina: os povos indígenas e o igualitarismo jurisdicional na Bolívia. In.: VERDUM, Ricardo (org.). Povos Indígenas: constituições e reformas políticas na América Latina. Brasília: IES, 2009. p. 45-67.

CORDANO, José Alberto Mujica. Discurso na Rio+20. Disponível em: <http:// umhistoriador.wordpress.com/2013/01/10/texto-do-discurso-proferido-por-jose-pepe-mujicanario20/>. Acessado em 06 de Junho de 2014.

DALMÁU, Rubén Martínez. El Nuevo Constitucionalismo Latinoamericano y el Proyecto deConstitución del Ecuador de 2008. In.: Alter Justicia: estudios sobre teoría y justicia constitucional. Ano 2, n. 1, p. 13-28, oct. 2008.

DUSSEL, Enrique. 1492 El Encubrimiento Del Otro: hacia El origen del "mito de La Modernidad. La Paz: Plural Editores, 1994.

FERNÁNDEZ-NOGUERA, Albert e DIEGO, Marcos Criado. La Constitución Colombiana de 1991 como Punto de Inicio Del Nuevo Constitucionalismo en América Latina. In.: Revista Estudos Socio-Jurídicos, Bogotá (Colombia), n. 13 (1), enero-junio de 2011. p. 15-49.

GARGARELlA, Roberto e COURTIS, Christian. El Nuevo Constitucionalismo Latinoamericano: promesas e interrogantes. Santiago: CEPAL, 2009.

GRIJALVA, Agustín. El Estado Plurinacional e Intercultural em La Constitución Ecuatoriana del 2008. In. Ecuador Debate 75. Quito-Ecuador, Dezembro de 2008. p. 49-62. Disponível em: <http://www.ecuadordebate.com/wp-content/ uploads/2010/06/Ecuadordebate75.pdf $>$. Acessado em: 17 de maio de 2015.

HUANACUNI, Fernando. Paradigma Occidental y Paradigma Indígena Originario. In.: Sumak Kawsay: recuperar el sentido de vida. ALAI, $n^{\circ} 452$, año XXXIV, II época, Quito, Ecuador, febrero 2010. 
KROHLING, Aloísio. Dialética e Direitos Humanos - múltiplo dialético: da Grécia à Contemporaneidade. Curitiba: Juruá Editora, 2014.

LANDER, Edgardo. Estamos Viviendo Una Profunda Crisis Civilizatoria. In.: Sumak Kawsay: recuperar el sentido de vida. ALAI, n 452, año XXXIV, II época, Quito, Ecuador, febrero 2010.

LEÓN T., Magdalena. Reactivación Económica para El Buen Vivir: un acercamiento. In.: Sumak Kawsay: recuperar el sentido de vida. ALAI, n 452 , año XXXIV, II época, Quito, Ecuador, febrero 2010.

LINEIRA, Álvaro Garcia. El Estado en Transición: bloque de poder y punto de bifurcación. In.: LINERA, Álvaro Garcia e outros. El Estado: campo de lucha. La Paz: Muela Del Diablo Editores, 2010.

A Potência Plebeia: ação coletiva e identidades indígenas, operárias e populares na Bolívia. São Paulo: Boitempo, 2010a.

MACAS, Luis. Sumak Kawsay: la vida en plenitud. In.: Sumak Kawsay: recuperar el sentido de vida. ALAI, nº 452, año XXXIV, II época, Quito, Ecuador, febrero 2010.

MAGALHÃES, José Luiz Quadros de. Estado Plurinacional e Direito Internacional. Curitiba: Juruá, 2012e.MAÍZ, Ramón. Nacionalismo y Multiculturalismo. Disponível em $<$ http://red.pucp.edu.pe/ridei/wp-content/uploads/biblioteca/081116.pdf>. Acessado em: 17 de Agosto de 2014.

MORAES, Germana de Oliveira e FREITAS, Raquel Coelho. O Novo Constitucionalismo Latino-Americano e o Giro Ecocêntrico da Constituição do Equador de 2008: os direitos de pachamama e o bem viver (sumak kawsay). In: MELO, Milena Petters e WOLKMER, Antonio Carlos (orgs.). Constitucionalismo Latino-Americano: tendências contemporâneas. Curitiba: Juruá, 2013.

OLIVÉ, León. Por una Auténtica Interculturalidad Basada em El Reconocimiento de La Pluralidad Epistemológica. In.: Pluralismo Epistemológico. La Paz: Muela del Diablo Editores, 2009. Editores, 2009a.

e OUTROS. Prólogo. In.: Pluralismo Epistemológico. La Paz: Muela del Diablo

Multiculturalismo y Pluralismo. México: Paidós, 1999.

Interculturalismo y Justicia Social. Mexico: UNAM, 2004.

PASTOR, Roberto Viciano e MARTÍNEZ DALMAU, Rubén. Aspectos Generales Del Nuevo Constitucionalismo Latinoamericano. In.: El Nuevo Constitucionalismo en América Latina: memorias del encuentro internacional el nuevo constitucionalismo (desafios y retos para el siglo XXI). Quito: Corte Constitucional Del Ecuador, 2010. p. 9-44. 


Corriente Doctrinal Sistematizada?. Disponível em: <
http://www.juridicas.unam.mx/wccl/ponencias/13/245.pdf>. Acessado em 01 de Agosto de 2014.

. Necessidad y Oportunidad en el Proyecto Venezolano de Reforma Constitucional (2007). In.: Revista Venezolana de Economía y Ciencias Sociales.vol. 14, n. 2, 2008, p. 102-132.

SANTOS, Boaventura de Sousa (org.). Reconhecer para Libertar: os caminhos do cosmopolitismo multicultural. Rio de Janeiro: Civilização Brasileira, 2003.

Para Além do Pensamento Abissal: das linhas globais a uma ecologia dos saberes. In: Revista Crítica de Ciências Sociais, n. 78, Outubro de 2007, p. 3-46.

. A Gramática do Tempo: para uma nova cultura política. $3^{\mathrm{a} e d}$. São Paulo: Cortez Editora, 2011.

Refundación del Estado en América Latina: perspectivas desde uma epistemología del sur. Buenos Aires: Antropofagia, 2010.

La reinvención del Estado y el Estado plurinacional. In.:OSAL (Buenos Aires: CLACSO) Año VIII, $\mathrm{N}^{\circ}$ 22, Setembro de 2007a. Disponível em:<http://bibliotecavirtual.clacso.org.ar/ar/libros/osal/osal22/D22SousaSantos.pdf $>$. Acessado em 21 de Agosto de 2012.

Para uma Concepção Multicultural dos Direitos Humanos. In.: Contexto Internacional. Rio de Janeiro, vol. 23, n. 1, jan/jun, 2001, p. 7-34.

Editores. 2009.

Pensar El Estado Y La Sociedad: desafios actuales. Buenos Aires: Waldhuter

Reinventar a Democracia. 2a ed. Lisboa: Gradiva, 1998.

. Reinventar a Democracia: entre o pré-contratualismo e o póscontratualismo.

Oficina do Centro de Estudos Sociais. nº 107. Coimbra, 1998a.

Os Processos de Globalização. In.: SANTOS, Boaventura de Sousa (org.) A Globalização e as Ciências Sociais. São Paulo: Cortez Editora, 2002.

SILVA, Heleno Florindo da. Teoria do Estado Plurinacional - o novo constitucionalismo latino-americano e os direitos humanos. Curitiba: Juruá Editora, 2014.

TAPIA, Luis. "Una reflexión sobre laidea de Estado plurinacional". In.: OSAL (Buenos Aires: CLACSO) Ano VIII, $\mathrm{N}^{\circ}$ 22, Setembro de 2007. Disponível em:<http://bibliotecavirtual.clacso.org.ar/ar/libros/osal/osal22/D22Tapia.pdf $>$. Acessado em 22 de Abril de 2015.

Tiempo, Poiesis y Modelos de Regularidad. In: Pluralismo Epistemológico. La Paz: Muela del Diablo Editores, 2009. 
. Pensando La Democracia Geopolíticamente. La Paz: Muela Del Diablo Editores, 2009.

VIEIRA, José Ribas. Refundar o Estado: o novo constitucionalismo latino-americano. In: Universidade Federal do Rio de Janeiro. Disponível em: <http://pt. scribd.com/doc/24243799/UFRJ-Novo-Constitucionalismo-Latino-Americano>. Acessado em 15 de Março de 2015.

WOLKMER, Antonio Carlos. Pluralismo Jurídico e Direitos Humanos: dimensões emancipatórias. In.: MARTÍNEZ, Alejandro Rosillo. Teoria Crítica dos Direitos Humanos no Século XXI. Porto Alegre: EDIPUCRS, 2008.

. Constitucionalismo e Direito Sociais no Brasil. São Paulo: Acadêmica, 1989.

. Pluralismo Jurídico: fundamentos de uma nova cultura do direito. $3^{\mathrm{a} e d . ~ S a ̃ o ~}$

Paulo: Alfa Ômega, 2001.

Pluralismo Jurídico, Direitos Humanos e Interculturalidade. In: Revista Sequência. N. 53, p. 113 a 128. Dezembro de 2006.

- Pluralismo Crítico e Perspectivas para um Novo Constitucionalismo na América Latina. In: MELO, Milena Petters e WOLKMER, Antonio Carlos (orgs.). Constitucionalismo Latino-Americano: tendências contemporâneas. Curitiba: Juruá, 2013.

Elementos para uma Crítica do Estado. Porto Alegre: Fabris, 1990.

e FAGUNDES, Lucas Machado. Tendências Contemporâneas do Constitucionalismo Latino-Americano: o estado plurinacional e pluralismo jurídico. In: Revista Pensar. Fortaleza, jul./dez. v. 16. n.2. p. 371-408. 2011.

1621-408. 2011. 